Article

\title{
Assessing Neighborhood Satisfaction and Social Capital in a Multi-Cultural Setting of an Abu Dhabi Neighborhood
}

\author{
Anfal Al-Ali ${ }^{1}$, Praveen Maghelal ${ }^{2, *(\mathbb{D})}$ and Khaled Alawadi ${ }^{2}$ \\ 1 Graduate Student, Sustainable Critical Infrastructure Program, Khalifa University, Abu Dhabi 127788, UAE; \\ anfal.a.08@gmail.com \\ 2 Sustainable Critical Infrastructure Program, Khalifa University, Abu Dhabi 127788, UAE; \\ khaled.alawadi@ku.ac.ae \\ * Correspondence: praveen.maghelal@ku.ac.ae; Tel.: +971552723407
}

Received: 28 March 2020; Accepted: 14 April 2020; Published: 15 April 2020

\begin{abstract}
Behavioral research studies propose that urban open spaces contribute to enhance sociability in urban areas. The urban areas in the city of Abu Dhabi are less appealing to attract vibrant activity and social life. This study investigates the role of the built environment in the enhancement of neighborhood satisfaction and social capital in a residential neighborhood of Abu Dhabi. A total of 145 residents were surveyed for their perception, attitude, and behavior. Regression analyses to predict the role of the built environment of the open space, as well as the ethnicity of respondents, on measures of neighborhood satisfaction and social capital were performed. Spatial data and audit tools were used to assess the lack of suitable built-environment in the study area. Results indicate that improvements to the built environment can improve both the social capital and neighborhood satisfaction of the urban residents of Abu Dhabi. Implications of this study include recommendations to enhance the experience of urban spaces in arid regions like Abu Dhabi. Recommendations include adding landscape elements, providing a comfortable walking environment, adding attractive locations and destinations, and a clean and safe environment with attractive buildings or homes.
\end{abstract}

Keywords: social capital; neighborhood satisfaction; built environment; open space; Abu Dhabi

\section{Introduction}

Effective planning and design of open spaces in urban areas can add significant value to its community. It can enhance the sense of community, social cohesion, and livability [1,2], and help improve people's physiology (heart rate and nerve activity) while reducing negative emotions and anxiety [3]. However, most literature neglects public areas such as plazas, linear corridors, and nature assets [4], especially since studies report that compactness and densification can create a more sustainable environment [5]. Street corners and vacant and undeveloped spaces can also form small open parks in an urban neighborhood [6] that can be used by residents, kids, and teenagers for recreational and leisure activities. Free access to such parks in an urban setting can influence people's leisure-time activities and reduce the effect of a sedentary lifestyle [7,8]. Additionally, green open spaces and vegetation appear to alleviate mental fatigue, as greener places reported a lower level of fear and violent and aggressive behaviors $[9,10]$.

Open spaces report significant economic impact on values of properties that have a visual connection to parks in comparison to those that do not or are located away from the park [11]. Conversely, attachment to one's neighborhood or social cohesion and participation in neighborhood groups or activities are reported to be influenced by the urban form or built environment of the 
neighborhood [12]. However, the perception of availability, use, and attractiveness of such spaces in the middle east, particularly in the capital city of the United Arab Emirates, Abu Dhabi, is limited at best.

Abu Dhabi is the largest of the seven emirates in the UAE federation system. The developed land of Abu Dhabi covers $972.45 \mathrm{~km}^{2}$ of the emirate. As of 2014, the urban population was estimated to be 1.14 million, while the rural population was 493,253 , and $81 \%$ of the total population was made up of expatriates (SCAD) [13]. In 2007, the Abu Dhabi Urban Planning Council (UPC) introduced the Vision Abu Dhabi 2030. One of the vision goals introduced in the charrette was to create a livable city by developing a good open space network [14]. Although the city launched many community facilities and public realm guidelines, implementation remains slow and limited. At present, there are no specific policies and regulations to improve the public spaces in the existing residential blocks. Additionally, there is very little understanding of what type of open space is preferred by the residents, and what kind of retrofit would enhance the social capital of the neighborhood. With the World Expo 2020 to be hosted in the UAE, all emirates, including Abu Dhabi, are involved in new development and redevelopment of the urban area. Outcomes from this can help recommend appropriate design and policy approaches that can improve the livability of these urban areas and improve the social sustainability of the neighborhoods.

Therefore, this study examines the relationship between the built environment (walkable open spaces) and the multi-cultural setting impact neighborhood satisfaction. This study also investigates the relationship of the built environment, multi-cultural setting, and neighborhood satisfaction on the social capital of a neighborhood in Abu Dhabi. This study further examines the characteristics of the built environment that exist in the study area using both audit and spatial measures to provide design and policy recommendations to enhance the perception of the built environment and neighborhood satisfaction and social capital of the neighborhood.

\section{Open Space in Abu Dhabi}

The problem of open space in the UAE started incrementally after the discovery of petroleum and the expansion of the city's urban boundary. The addition of technological improvements and the entry of automobiles caused a massive expansion that led to the development of an automobile-oriented town [15]. Thus, streets became major linkages between destinations by a car while pedestrian infrastructure was neglected to a great extent. Urban residents face challenges such as unshaded pathways, inconvenient walking environment, insufficient natural elements, and unavailability of physical features that support children and adults $[16,17]$. These missing elements in urban open spaces have led to the segregation of residents from their surrounding outdoor environment [18]. Such segregation reduces social interactions and communication and decreases opportunities for physical activity. The consequences do not only affect the quality of social life and physical activity, but can also lead to health and psychological problems. According to a US-UAE Business Council study in 2014, 90\% of deaths in the UAE are caused by a sedentary, chronic lifestyle that encourages diabetes, hypertension, and cancer. Physical activity decreases chronic diseases such as diabetes, heart diseases, high blood pressure, and cancer, as well as psychiatric illness such as anxiety, stress, and depression. Therefore, improving urban open space has long-term implications for the community, such as enhancing social capital, the interaction between people, connectivity, and walkability. Planning literature recommends that having access to a neighborhood park and natural surroundings can affect mental and physical health, reduce chronic diseases and stress, and elevate individual performance $[19,20]$.

\section{Benefits of Public Open Space}

\subsection{Physical Activity and Public Health}

Open spaces such as parks and accessible shaded pathways have been investigated for their relation with physical activity and overall public health. It has been reported that small local parks in urban 
settings could influence people's leisure-time activities and enhance active living [21]. Additionally, high density of residential destinations, a mix of land uses, and diversity in destinations all have an impact on adult physical activities [22]. Open spaces have been reported to reduce sedentary behavior and encourage higher levels of physical activity for residents.

\subsection{Neighborhood Satisfaction}

Neighborhood satisfaction refers to the overall evaluation of the neighborhood environment by its residents. Research on neighborhood satisfaction has investigated the personal, social, and psychological factors, but has overlooked the physical environment that is associated with neighborhood satisfaction [23]. A physical environment that supports non-motorized modes of travel influences an individual's perception and neighborhood satisfaction. For example, higher walkability can be observed in neighborhoods that reported higher density levels, diversity in land-use, better street connectivity, accessibility, and safety [24]. Additionally, a well-maintained neighborhood, availability of recreational destinations and parking space, and availability and proximity of public amenities and commercial services have been reported to have a positive impact of the on neighborhood satisfaction [25].

\subsection{Social Capital}

Social capital is the outcome of trust and reciprocity among residents through social interactions, which leads to higher levels of political involvement, volunteerism and social get-togethers with friends and families. Research indicates linkages between health, democracy, crime, and economy with social capital [26]. However, its relation to the physical environment is understudied.

Well-planned public open spaces have been reported to have a positive relationship with social capital. The greenness of common areas between buildings plays a significant role in community growth, safety, and social relations, and the presence of nature attracts more resident to conduct outdoor activities compared to places that are devoid of nature [19]. Providing a gathering place where people can meet, interact, and communicate or conduct some physical activities can significantly enhance social capital. For instance, Kweon, Sullivan, and Wiley [27] reported that the availability of trees and grass in common spaces within the neighborhood boosts social interactions and ties between older adult residents. An observational study in public open spaces in 59 neighborhoods ( 27 neighborhoods with natural features while 32 were barren) [28] reported that the presence of trees influences social interactions between residents, which leads to enhanced vitality. Therefore, the presence of nature was reported to improve social interactions, relationships, and activities within neighborhoods. Such neighborhoods enhance the social capital of the urban area and are assessed by understanding the perception and accessibility of its surroundings by its residents.

\subsection{Accessibility to Open Space}

Proximity to activity areas and recreational facilities plays a vital role in residents' attainment of recommended physical activity [8]. Access to parks encourages higher levels of physical activity among residents of all ages and gender [29]. Additionally, the activity level of neighborhood residents' increases correspondingly with the number of parks within one hectare [30]. Both ease of access and number of parks add to the aesthetic value and to residents' desire to participate in activities in the public area and engage in more walking and biking in the community [31].

In summary, the characteristics of open spaces in the surrounding neighborhood have a significant influence on people's interaction and sociability. In doing so, several studies have addressed different open space elements, such as natural features and the aesthetic value of the space. While the influence of open spaces on activity level is quite clear, the influence of neighborhood surroundings on the social capital of the neighborhood remains to be investigated. This study, therefore, examines the impact of urban open spaces on the perception of satisfaction of the neighborhood and social capital in the city of Abu Dhabi. 


\section{Method}

\subsection{Study Area}

This study investigates the social capital and neighborhood satisfaction of an urban block, $\mathrm{Al}$ Za'franah, in Abu Dhabi. Al Za'franah is a residential neighborhood that was developed in 1981 [32]. It consists of three sectors (sectors E37, E38, and E38-01), for a combined area of $0.72 \mathrm{~km}^{2}$. It is located on the island of Abu Dhabi (Figure 1), and according to Statistical Center of Abu Dhabi [13] census data, it has a total population of 6021 (3124 males and 2897 females). It is surrounded by the Eastern Mangrove Lagoon National Park from the north and by residential neighborhoods from the other sides.

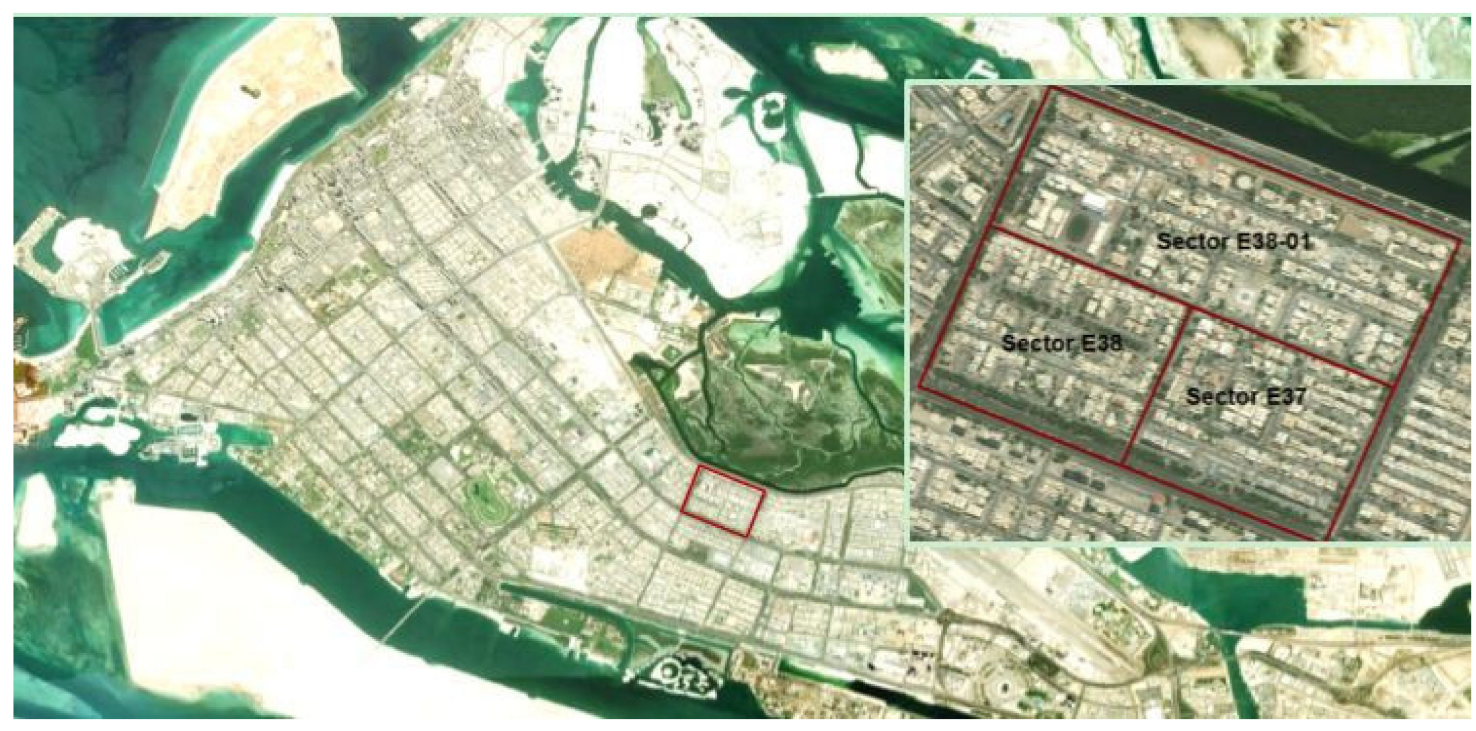

Figure 1. Satellite image of the study area.

\subsection{Survey Content and Administration}

The perception of the built environment was measured using a combination of questions extracted from the Neighborhood Environment Walkability Survey (NEWS) [33], and the Parks and Recreation Areas Self-Report Survey [34]. Social capital was assessed by the questions from the Social Capital Integrated Questionnaire developed by Grootaer [35]. These survey instruments have reported good reliability and validity and were translated into Arabic and Urdu for the residents (two common local spoken languages). Physical features of the open space were measured using spatial data in GIS and an audit tool (Checklist Audit Tool) [36].

The survey included a total of 78 questions grouped into five sections. The first section tested participants' walking behavior to different types of destinations that were located within 10- to 15-minute walking distance from participants' residence (seven items). The second section examined participants' perceptions regarding their neighborhood (38 items). It consisted of five sub-sections, including places for walking and cycling, neighborhood surroundings, safety from traffic, safety from crime, and function. The third section evaluated the level of neighborhood satisfaction (18 questions). The fourth section included five sub-sections including groups and networks, trust and solidarity, collective action and cooperation, social cohesion and inclusion, and empowerment, which all together assess the social capital of the place (14 questions). The last section included basic demographic questions (six items). The survey was distributed at different times of the day and evenings, both on weekdays and weekends. Volunteer residents (convenient sampling) were surveyed during the wintertime from the 20th of December, 2015 to the 31st of January, 2016. 


\subsection{Statistical Analyses}

Built environment measures report a high correlation, especially when several measures are included in the same analysis $[37,38]$. To avoid the effect of covariance, Confirmatory Factor Analysis (CFA) was performed to derive the factor scores of five latent variables (independent variables): accessibility, perception, neighborhood surrounding, safety from crime, and safety from traffic. The neighborhood satisfaction was estimated as the average satisfaction of 18 characteristics of the neighborhood questions. The alpha for neighborhood satisfaction reported a value of 0.7914 . The social capital was calculated as the average of six themes: (1) Groups and networks; (2) Trust and Solidarity; (3) Collection Action and Cooperation; (4) Social Cohesion and Inclusion; (5) Sociability; and (6) Empowerment and Political Action. Regression analysis was performed to examine what built environment perceptions relate to neighborhood satisfaction. Another regression analysis predicted if neighborhood satisfaction and factors of the built environment relate to social capital. Further to this analysis, this study assessed the built environment using spatial and environmental audits to identify what built environment measures need improvement to enhance neighborhood satisfaction and social capital of the study area.

\section{Results and Discussion}

\subsection{Respondents Characteristics}

A total of 145 fully completed surveys were collected which included 75 male and 70 female participants. It appears that residents of the study area are multi-national. The majority of study area residents are Southeast Asians, who represent $58 \%$ of the population, followed by individuals from the Gulf Cooperation Council (GCC), which included individuals from Egypt, Jordon, Syria, and Palestine $(18 \%)$ and others $(15 \%)$. Additionally, about $10 \%$ of the local Emirati population responded to the survey, which represents the general distribution of the population of Abu Dhabi. Table 1 summarizes the respondents' characteristics.

Table 1. Respondent demographic information.

\begin{tabular}{llll}
\hline \multicolumn{1}{c}{ Measures } & \multicolumn{1}{c}{ Male } & \multicolumn{1}{c}{ Female } & \multicolumn{1}{c}{ Total } \\
\hline Age & & & \\
$21-24$ & $18(12.4 \%)$ & $14(9.6 \%)$ & $32(22.1 \%)$ \\
$25-34$ & $26(17.9 \%)$ & $38(26.2 \%)$ & $64(44.1 \%)$ \\
$35-44$ & $26(17.9 \%)$ & $17(11.7 \%)$ & $43(29.7 \%)$ \\
$45-64$ & $5(3.4 \%)$ & $1(0.7 \%)$ & $6(4.1 \%)$ \\
Education & & & \\
High-school & $29(20 \%)$ & $14(9.6 \%)$ & $43(29.7 \%)$ \\
Bachelor & $30(20.7 \%)$ & $36(24.8 \%)$ & $66(45.5 \%)$ \\
Masters & $15(10.3 \%)$ & $14(9.6 \%)$ & $29(20 \%)$ \\
Doctoral & $1(0.7 \%)$ & $4(2.8 \%)$ & $5(3.4 \%)$ \\
Others & - & $1(0.7 \%)$ & $1(0.7 \%)$ \\
NR & - & $1(0.7 \%)$ & $1(0.7 \%)$ \\
HH Income & & & \\
$<10,000$ & $32(22.1 \%)$ & $37(25.5 \%)$ & $69(47.6 \%)$ \\
10,000-30,000 & $33(22.8 \%)$ & $17(11.7 \%)$ & $50(34.5 \%)$ \\
$>30,000$ & $4(2.8 \%)$ & $1(0.7 \%)$ & $5(3.4 \%)$ \\
NR & $6(4.1 \%)$ & $15(10.3 \%)$ & $21(14.5 \%)$ \\
Ethnicity & & & \\
Local & $9(6.2 \%)$ & $5(3.4 \%)$ & $14(9.7 \%)$ \\
Asian & $50(34.5 \%)$ & $34(23.4 \%)$ & $84(57.9 \%)$ \\
GCC & $9(6.2 \%)$ & $17(11.7 \%)$ & $26(17.9 \%)$ \\
Other & $7(4.8 \%)$ & $14(9.7 \%)$ & $21(14.4 \%)$ \\
\hline & & &
\end{tabular}




\subsection{Principle Component Analysis}

The confirmatory factor analysis was performed to derive the factor scores for each latent variable identified in the NEWS questionnaire. A threshold of 0.5 was used to determine the group of variables that best explained the latent variables of accessibility, perception, neighborhood surroundings, safety from traffic, and safety from crime (Table 2). Standardized factor loading of 0.3 or 0.4 and above can be used operationally as a salient factor loading for a latent variable [39] (p. 115). The perception factor reported the lowest reliability coefficient (alpha) of 0.562 , while the crime safety factor reported the highest reliability coefficient of 0.676 . A meta-analysis of studies reporting the reliability coefficient found that the constructs of perception, values, belief, or behavior tend to report lower alpha values compared to other constructs such as intentions and attitude [40]. However, the likelihood ratio (chi-squared test) reported statistical significance for all five latent variables.

Table 2. Built environment constructs from confirmatory factor analysis.

\begin{tabular}{|c|c|c|c|c|c|}
\hline Variables & Accessibility & Perception & Surrounding & Traffic Safety & Crime Safety \\
\hline Walkability to stores & 1.000 & - & - & - & - \\
\hline Walkability to other places & 1.208 & - & - & - & - \\
\hline Walkability to transit stop & 1.566 & - & - & - & - \\
\hline Walkability to non-gov. services & 2.964 & - & - & - & - \\
\hline Walkability to gov. services & 2.055 & - & - & - & - \\
\hline Availability of sidewalks & - & 1.000 & - & - & - \\
\hline Availability of bicycle or pedestrian trails & - & 2.505 & - & - & - \\
\hline Separation of sidewalks by cars & - & 3.070 & - & - & - \\
\hline Separation of sidewalks by Grass/dirt & - & 1.645 & - & - & - \\
\hline Trees along streets & - & - & 1.000 & - & - \\
\hline Trees shade on sidewalks & - & - & 1.687 & - & - \\
\hline Free of litter & - & - & 0.541 & - & - \\
\hline Attractiveness of natural sights & - & - & 0.983 & - & - \\
\hline Attractiveness of buildings/homes & - & - & 0.683 & - & - \\
\hline Traffic along home street & - & - & - & 1.000 & - \\
\hline Traffic along nearby streets & - & - & - & 0.788 & - \\
\hline Air pollution & - & - & - & 0.295 & - \\
\hline Lighting at night & - & - & - & - & 1.000 \\
\hline Interaction with others & - & - & - & - & 1.296 \\
\hline High crime rate & - & - & - & - & 1.249 \\
\hline Safety during the day & - & - & - & - & 0.947 \\
\hline Safety during the night & - & - & - & - & 0.629 \\
\hline Reliability Coeff. (Cronbach's alpha) & 0.671 & 0.562 & 0.601 & 0.669 & 0.676 \\
\hline Likelihood Ratio (Model vs. Saturated) & $9.14 *$ & $9.26^{* * *}$ & $10.25^{*}$ & $10.59^{* * * *}$ & $10.17^{*}$ \\
\hline
\end{tabular}

\subsection{Regression Analysis}

Two regression analyses tested the significance of the perception of built environment variables for the neighborhood satisfaction, and the impact of both on social capital (Table 3). The regression models reported statistical significance. Additionally, tests for violation of assumptions of Ordinary Least Square (OLS) regression was performed. The section below reports the outcome of the regression analysis on neighborhood satisfaction while the following section reports the regression outcomes on social capital.

\subsubsection{Predicting Neighborhood Satisfaction}

Neighborhood satisfaction was calculated as the average of all the responses to 18 questions with responses ranging from 1 to 6 , with an average value of 3.66 and an alpha of 0.791 . This indicates the residents were closer to being somewhat satisfied with their neighborhood. The regression model predicting this variation with ethnic group and built environment as primary determinants and the socio-demographic information as the control variable was analyzed. The regression model explained $32.8 \%$ of the variance and was statistically significant at $\mathrm{p}<0.001$ (Table 3 ). The built environment constructs and the ethnicity measures reported statistical significance in predicting neighborhood 
satisfaction. Access, perception, and surrounding constructs reported a positive association with neighborhood satisfaction. By contrast, the ethnic groups of Asians and Others reported negative associations in comparison to the locals in the neighborhood. This indicates the built environment constructs play a decisive role in the satisfaction of residents living in a neighborhood, and improving the existing built environment can enhance their level of satisfaction. These results concur with previous studies that reported a positive relation to the neighborhood satisfaction if it had good accessibility and better perception of its surrounding [41,42]. Hence providing open spaces that are easily accessible and attractive can enhance the satisfaction levels of the residents of that neighborhood.

Table 3. Predictors of neighborhood satisfaction.

\begin{tabular}{|c|c|c|c|c|}
\hline \multirow{2}{*}{\multicolumn{2}{|c|}{ Variables }} & \multicolumn{3}{|c|}{ Neighborhood Satisfaction (Dep. Variable) } \\
\hline & & Coef & \multirow[t]{2}{*}{ Std Error } & \multirow[t]{2}{*}{$\mathbf{t}$} \\
\hline Ethnicity & & & & \\
\hline & GCC & -0.316 & 0.242 & -1.31 \\
\hline & Asian & $-0.416^{* *}$ & 0.206 & -2.02 \\
\hline & Other & $-0.679 * * *$ & 0.258 & -2.63 \\
\hline \multicolumn{5}{|l|}{ Age } \\
\hline & 25-34 years & 0.132 & 0.161 & 0.82 \\
\hline & $35-44$ years & 0.047 & 0.177 & 0.26 \\
\hline & 45-64 years & 0.418 & 0.298 & 1.40 \\
\hline & 65 years or older & -0.118 & 0.104 & -1.13 \\
\hline \multicolumn{5}{|l|}{ Education } \\
\hline & Bachelor's Degree & -0.114 & 0.149 & -0.76 \\
\hline & Master's Degree & -0.057 & 0.172 & -0.33 \\
\hline & Doctoral Degree & 0.074 & 0.331 & 0.22 \\
\hline & Other Degree & $-1.796^{* * * *}$ & 0.63 & -2.85 \\
\hline \multicolumn{5}{|l|}{ Income (AED) } \\
\hline & $10-30 \mathrm{~K}$ & -0.195 & 0.125 & -1.56 \\
\hline & $>30 \mathrm{~K}$ & 0.032 & 0.293 & 0.11 \\
\hline \multicolumn{5}{|c|}{ Built Environment } \\
\hline & Access & $0.449 *$ & 0.235 & 1.91 \\
\hline & Perception & 0.544 * & 0.287 & 1.90 \\
\hline & Surrounding & $0.291^{* *}$ & 0.124 & 2.35 \\
\hline & Crime & 0.384 & 0.483 & 0.79 \\
\hline & Traffic Safety & 0.000 & 0.071 & 0.00 \\
\hline \multicolumn{2}{|c|}{ Number of Observations } & \multicolumn{2}{|c|}{123} & \\
\hline \multicolumn{2}{|l|}{$\mathrm{F}(18,104)$} & \multicolumn{2}{|c|}{2.82} & \\
\hline \multicolumn{2}{|l|}{ Prob $>$ F } & \multicolumn{2}{|c|}{0} & \\
\hline \multicolumn{2}{|l|}{ R-Squared } & \multicolumn{2}{|c|}{0.328} & \\
\hline \multicolumn{2}{|l|}{ Adj R-Squared } & \multicolumn{2}{|c|}{0.212} & \\
\hline \multicolumn{2}{|l|}{ Root MSE } & \multicolumn{2}{|c|}{0.582} & \\
\hline
\end{tabular}

Conversely, a unit increase in the number of Southeast Asians and other non-GCC residents in comparison to locals tends to report a lower neighborhood satisfaction. This may indicate a case of social and cultural segregation of perception of non-locals living in cohabitation with the Emirati population [43]. Studies show the existence of social segregation in the Emirate of Abu Dhabi, which can influence this negative relation. While recent studies call for more inclusionary planning [44,45], it seems the non-locals are not satisfied living in a neighborhood with the local population.

While acknowledging the socio-cultural segregation, the results of this analysis indicate that the built environment constructs, such as accessibility within the neighborhood, perception of the built environment, and the surroundings within the neighborhood play an essential role in improving the satisfaction of the neighborhood. Hence design approaches should acknowledge these personal and cultural needs when proposing new open spaces in the neighborhood of Abu Dhabi. 


\subsubsection{Predicting Social Capital}

Social Capital was calculated as the average of the sum of each construct used to predict social capital. The responses report an average of 5.69 (range of 1 to 9.5) with an alpha value of 0.713 . The primary predictor variables included the five constructs of the built environment, the ethnic groups, and the neighborhood satisfaction variable, while controlling for the socio-demographic characteristics of the respondents. A multi-collinearity test was performed to exclude variables with high correlation. However, none of the predictive variables included in the model reported a high association.

The regression model explained $28 \%$ of the variance and was statistically significant at $\mathrm{p}<0.010$ (Table 4). It has to be noted that social capital is a complex measure influenced by complex indicators, including political affiliation, social cohesion, family network, etc. [26]. Only constructs that relate to the built environment and neighborhood satisfaction were included in this analysis.

Table 4. Predictors of social capital.

\begin{tabular}{|c|c|c|c|c|}
\hline \multirow{2}{*}{\multicolumn{2}{|c|}{ Variables }} & \multicolumn{3}{|c|}{ Social Capital (Dep. Variable) } \\
\hline & & \multirow[t]{2}{*}{ Coef } & \multirow[t]{2}{*}{ Std Error } & \multirow[t]{2}{*}{$\mathbf{t}$} \\
\hline Ethnicity & & & & \\
\hline & GCC & $0.959 * *$ & 0.421 & 2.28 \\
\hline & Asian & $1.406^{* * * *}$ & 0.363 & 3.87 \\
\hline & Other & 0.683 & 0.460 & 1.48 \\
\hline \multicolumn{5}{|l|}{ Age } \\
\hline & 25-34 years & -0.253 & 0.279 & -0.91 \\
\hline & 35-44 years & -0.466 & 0.305 & -1.53 \\
\hline & 45-64 years & -0.523 & 0.518 & -1.01 \\
\hline & 65 years or older & 0.100 & 0.181 & 0.55 \\
\hline \multicolumn{5}{|l|}{ Education } \\
\hline & Bachelor's Degree & 0.378 & 0.258 & 1.47 \\
\hline & Master's Degree & 0.575 * & 0.297 & 1.93 \\
\hline & Doctoral Degree & -0.735 & 0.571 & -1.29 \\
\hline & Other Degree & $2.507^{* *}$ & 1.128 & 2.22 \\
\hline \multicolumn{5}{|l|}{ Income (AED) } \\
\hline & $10-30 \mathrm{~K}$ & 0.352 & 0.218 & 1.61 \\
\hline & $>30 \mathrm{~K}$ & 0.388 & 0.506 & 0.77 \\
\hline \multicolumn{5}{|c|}{ Built Environment } \\
\hline & Access & -0.411 & 0.412 & -1.00 \\
\hline & Perception & -0.207 & 0.503 & -0.41 \\
\hline & Surrounding & 0.300 & 0.219 & 1.37 \\
\hline & Crime & $-1.716^{* *}$ & 0.836 & -2.05 \\
\hline & Traffic Safety & -0.058 & 0.123 & 0.47 \\
\hline \multicolumn{2}{|c|}{ Neighborhood Satisfaction } & $0.487^{* * * *}$ & 0.169 & 2.88 \\
\hline \multicolumn{2}{|c|}{ Number of Observations } & \multicolumn{2}{|c|}{123} & \\
\hline \multicolumn{2}{|l|}{$\mathrm{F}(18,104)$} & \multicolumn{2}{|c|}{2.13} & \\
\hline \multicolumn{2}{|l|}{ Prob $>$ F } & \multicolumn{2}{|c|}{0.008} & \\
\hline \multicolumn{2}{|l|}{ R-Squared } & \multicolumn{2}{|c|}{0.28} & \\
\hline \multicolumn{2}{|l|}{ Adj R-Squared } & \multicolumn{2}{|c|}{0.15} & \\
\hline \multicolumn{2}{|l|}{ Root MSE } & \multicolumn{2}{|c|}{1} & \\
\hline
\end{tabular}

Ethnic groups, the built environment, and neighborhood satisfaction reported significant statistical relations with the social capital of the neighborhood. While the ethnicity of the respondent and the neighborhood satisfaction reported a positive association with social capital, perception of crime reported a negative association. With a unit increase in perception of crime, the social capital of the neighborhood tends to reduce by $1.7(\mathrm{p}<0.05)$. Crime rates impact people's perception of the community they live in, and hence crime prevention can improve the social capital of the neighborhoods. 
Individuals with origins from Southeast Asia and the GCC, in comparison to the locals, report a positive association with the social capital of the neighborhood. It is again indicative of the social and cultural differences that are specific to the region. Most locals prefer, culturally, to live in neighborhoods that are developed primarily for the Emirati population. The UAE government provides incentives and support to the local population to construct or develop their residences in the subdivisions identified for the local population [46,47]. Most Southeast Asians and non-local Arabic population live in or close to the city center and do not have clear communities for individuals from their country of origin. Such a mix, studies report, creates higher social capital among individuals of a community [48].

Neighborhood satisfaction reported having a positive and significant relation (0.49) with social capital at $\mathrm{p}<0.001$. In other words, individuals with high neighborhood satisfaction report to add to the social capital of a place. Additionally, the built environment factors such as accessibility, perception, and surrounding of the neighborhood did not report significance because of the moderating effect of neighborhood satisfaction. Moderating variables tend to change the significance of the relationship of built environment variables as reported by previous studies [38]. Attention to improving the satisfaction of the residents of the neighborhood can improve the social capital of the neighborhood.

In summary, built environment factors influence neighborhood satisfaction, which in turn reports a significant relationship with social capital. While the individual built environment factors tend to report multi-collinearity and tend to be co-dependent [37], for the predictive model, the analysis of the existing built environment can provide guidance to propose design and policy solutions that can improve the overall quality of life of the residents of the neighborhood. The assessment of the neighborhood for these environmental factors was conducted using both spatial analysis and environmental audits.

\subsection{Analyzing Neighborhood Surroundings: Spatial Analysis and Environmental Audit}

Spatial analysis and the audit of the existing built environment can help identify specific recommendations to enhance the levels of satisfaction with the neighborhood and improve the social capital of the open area of Abu Dhabi. Three characteristics of the built environment-land-use mix, connectivity, and open area-were determined using spatial analysis. The audit tool used was the Checklist Audit tool developed by Brownson et al. [35] to assess the built environment in the neighborhood.

\subsubsection{Spatial Assessment}

\section{Land-Use Mix}

The study area is $0.72 \mathrm{~km}^{2}$, of which $45.4 \%$ is built up (Figure 2). Spatial analysis indicates that the study area contains various uses besides residential land-use, such as commercial, mixed-use, governmental, educational, recreational, health, religious, and utility uses. Residential use is $76.41 \%$ of the total developed land, followed by educational land use (10.81\%). Religious use (mosques) is $4.15 \%$ of all land-uses and is distributed at various locations in the study area. However, commercial and mixed-use lands are clustered in one area and altogether total only $2.27 \%$ of the entire developed land. The land-use mix was calculated using the following formula:

$$
\text { Land-use mix }=-\left[\left(\sum_{1}^{n}(p) * \ln (p)\right) / \ln (n)\right]
$$

where $\mathrm{p}$ refers to the proportional area for each use and $\mathrm{n}$ refers to the number of parcels. The study area has a land-use mix value of 0.16 , which indicates a very low mix of land-use, where 1 indicates a high land-use mix and 0 no mix of uses in the site. 


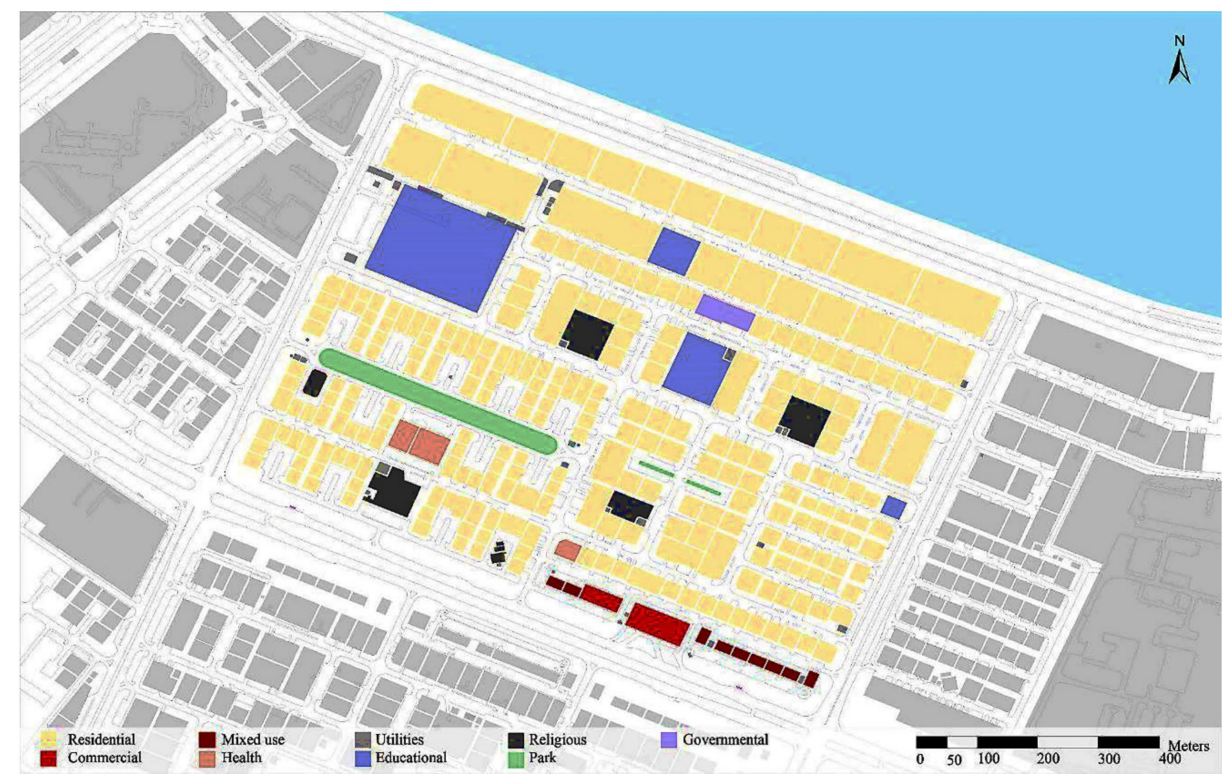

Figure 2. Land-use of the study area.

\section{Connectivity}

The study area has a total of 20 interconnected streets with a total length of $7832.9 \mathrm{~m}$ (minimum length of $120.2 \mathrm{~m}$ and a maximum length of $943.4 \mathrm{~m}$ ), and an average length of $391.6 \mathrm{~m}$. Interior streets in the study area are narrow two-way streets of $8 \mathrm{~m}$ in width with 27 intersections (3-way and 4 -way intersections) and three cul-de-sacs. The connected node ratio value is 0.9 , which gives a good indication of network connectivity. However, Figure 3 shows the unequal distribution of intersections throughout the study area. The link-node ratio value is 0.67 (the perfect value is 2.5), which indicates a low connectivity ratio [49]. Pedestrian walkways vary between 0.8 meters to 11.2 meters depending on the house set-back from the street. They are interrupted by driveways for cars, which affect the continuity of the sidewalk.

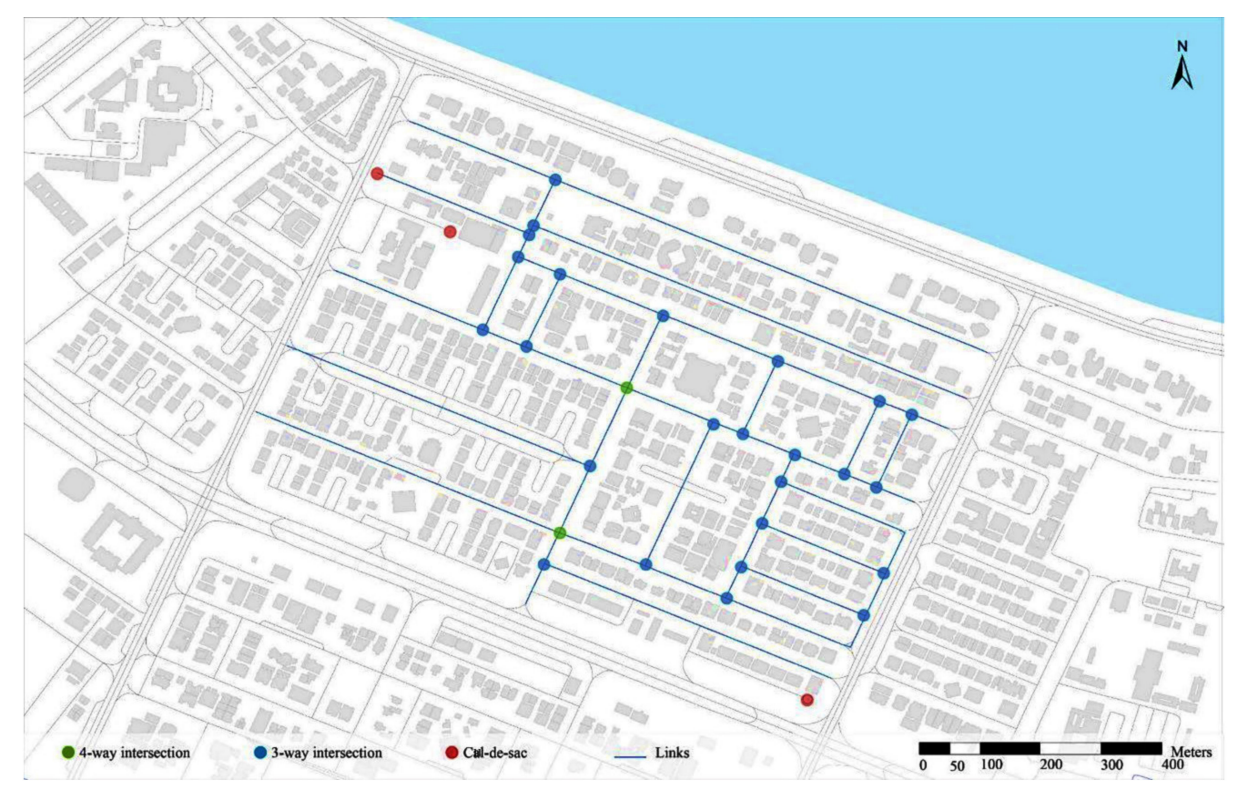

Figure 3. Study area connectivity. 


\section{Open Space}

Spatial analysis of open space revealed that the total open area is $0.38286 \mathrm{~km}^{2}$, representing both private and public open areas (Figure 4). Paved areas are 11.5\% of the total open area, and $10.4 \%$ of the open area is used for parking, while green open areas are only $15.6 \%$ of the total open area. This indicates that very little of the open space is used as shaded pathways, alleyways, or walkways with trees and green spaces. Studies indicate that such spaces enhance the levels of neighborhood satisfaction are and hence critical for its residents to be active in their community [50].

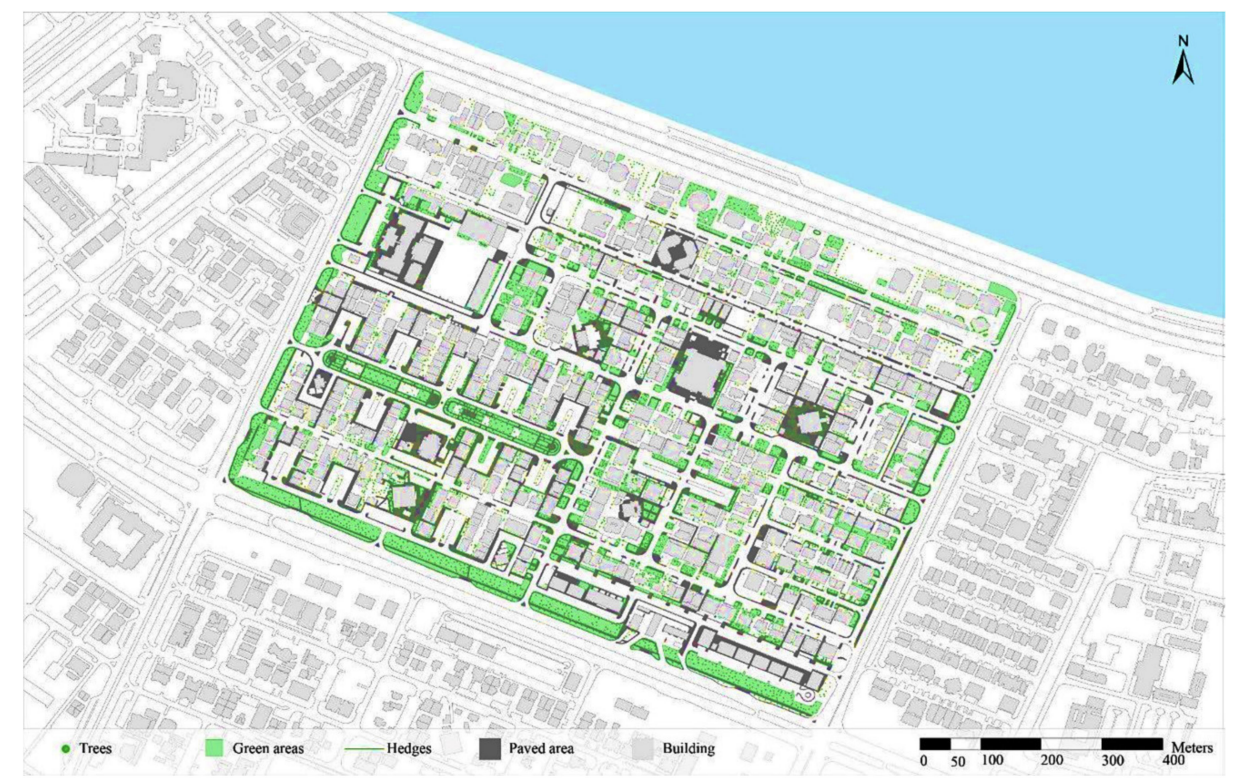

Figure 4. Study area open space plan.

\subsubsection{Audit Tool Assessment}

The Checklist Audit tool developed by Saint Louis University School of Public Health [36] was used to audit the neighborhood to understand the characteristics of land use, transportation, facilities, aesthetics, signage, and social environment of the urban block under study (Table 5).

Table 5. Environmental audit of study area.

\begin{tabular}{lll}
\hline \multicolumn{1}{c}{ Variable } & Quality & \multicolumn{1}{c}{ Comment } \\
\hline Residential & Good & 4 out of 6 destinations available \\
Public/governmental & Moderate & 8 out of 13 destinations available \\
Commercial & Moderate & 12 out of 21 destinations available \\
Recreational & Poor & 3 out of 9 destinations available \\
Natural features & Poor & 1 out of 4 destinations available \\
Walkability & Moderate & Depends on houses setbacks \\
Bikability & Poor & No bike lanes are available \\
Street connectivity & Poor & Not the interconnected street system. Many closed loops \\
Crossing aids & Poor & and cul-de-sacs. \\
Traffic calming devices & Poor & No/rare crosswalks (marking) \\
Street lighting & Moderate & Available on the sides of the streets only, not alleyways. \\
Recreational facilities & Moderate & Two small pocket parks \\
Recreational equipment & Moderate & Only those available at the park \\
Amenities & Poor & No public toilets, vending machines, or other amenities \\
Attractive features & Moderate & Trees available, but not well planned \\
Comfort features & Poor & Only in the park (benches, shade trees, and elements) \\
Air pollution & Good & No air pollution \\
Noise pollution & Good & No noise pollution \\
Physical disorder & Good & No significant physical disorder found \\
Signage & Poor & Only stop sign, and yield \\
Social activities & Good & People of different ages were present, \\
& & People conducting various physical activities were present \\
\hline
\end{tabular}


Land Use

The study area shows mostly a mix of residential building types with very little integration of other land uses (four of six residential types were visible). Retail and commercial destinations provide residents with their daily essentials (12 of 21 commercial and retail establishments were visible). However, the area lacks large commercial destinations such as shopping malls, theaters, and hotels. It also provides the essential public and governmental services that are needed for educational, religious, and health purposes ( 8 of 13). Only one small park that includes playgrounds and a sports court exists for recreational use by the community. There is a lack of green spaces between buildings (all green spaces were either inside the park or little private parks in front of individual villas) with all parking located on-street and not sufficient.

\section{Transportation}

All of the streets in the study area are two-way lanes, $8 \mathrm{~m}$ in width with street lights on each side. Most roads are connected by three-way intersections, in addition to some cul-de-sacs and closed loops. Additionally, there are no walking or cycling paths, except for the occasional building setbacks. There are two public bus stops on the south side of the site. Traffic calming approaches have not been incorporated throughout the study area, which can discourage the use of the street for walking or biking. In all, the street network and cross-section do not support safe non-motorized modes of travel within the study area.

Facilities

There are no other open area facilities available other than the two pocket parks in the study area. The park contains playgrounds, green areas, sitting areas, one small sports court, and trash bins. However, it lacks picnic tables, water fountains, restrooms, and vending machines. These amenities add to the convenience of the use of public open spaces and hence can be included in the parks to enhance social activities in the area.

Aesthetics

There are no considerable attractive natural or artificial features in the site, except for those available in the pocket park, in addition to trees and hedges available randomly in the study area. Although very little air or noise pollution was observed during the study period, the area generally lacks shade from trees during the daytime. The study area seemed well maintained generally, as there were no graffiti or broken or discarded items, with very little litter on the site.

Signage

Although the study area had stop signs and yield signs to direct driving at intersections, cautionary warning signs such as public parks, crosswalks, speed limits, and children play areas can make the neighborhood safe for children to walk and play in the community.

\section{Social Environment}

The researcher noticed that the area is usually active. People from different age groups engaged in various types of activities, such as sitting, walking, jogging, talking, playing, studying, and watching over younger kids. Building setbacks were used by residents to engage in casual sports activities.

\section{Conclusions}

The built environment constructs influence neighborhood satisfaction, which in turn has a positive impact on the social capital of the community. This study adds to the understanding of factors related to the improvement of the social capital of a location. Built environment constructs, such as accessibility 
to destinations, perception of the environment, and the neighborhood surroundings influence the satisfaction of the residents in a community.

To enhance accessibility, neighborhoods should provide opportunities to travel to increased daily destinations for its residents, such as local stores, public recreation centers (parks), and administrative destinations such as banks and post offices [8].

Positive perception of the neighborhood is critical for individuals to feel good about their neighborhood. The perception of availability and safe use of sidewalks enhances neighborhood satisfaction. Henceforth, sidewalks clear of litter, shaded walkways, trees, a safe distance from traffic and a well-connected pedestrian network should be planned for the residents of neighborhoods.

Additionally, neighborhoods that are perceived to be safe from crime highly correlated with neighborhood satisfaction [23]. It is not necessarily the direct impact of crime, but even the physical environment that can create an impression of crime, which is related to negative satisfaction with the neighborhood. Developing and maintaining clean and aesthetically appealing surroundings of open space can reduce the indirect effect of the perception of crime and can improve the levels of neighborhood satisfaction.

The cultural mix of a neighborhood has a positive impact on social capital but a negative relation with neighborhood satisfaction. Social segregation in the UAE has been reported in many recent studies that could make the perceptions of Emirati and non-Emirati, and especially the non-Arabic population, to be socially and culturally different. Recent studies debate the cultural integration of these ethnicities as a community [51]. For example, the planning system in the UAE separates citizens from expatriates; natives live in neighborhoods subsidized by the government, while expatriate housing is provided by the market. In addition, providing various housing types for different ethnicities and income levels in one area is culturally inappropriate. The desire for privacy and cultural homogeneity is firmly rooted in citizen's traditions. However, the cultural mix within the community adds to the social capital of the neighborhood. It can improve the trust and solidarity, social cohesion and inclusion and empowerment across all individuals irrespective of their country of origin [52,53].

Henceforth, improving the neighborhood while being sensitive to the cultural and social needs of its residents can improve both neighborhood satisfaction and the social capital of the neighborhood. Some specific recommendations include adding trees, creating a comfortable walking environment, increasing the number of attractive locations and destinations, a clean and safe environment, and aesthetic architecture of buildings or homes.

Both the spatial analysis and audit tool assessment confirmed a low integration of land-use mix in the urban block. The low land-use mix value highlights lack of destinations and facilities in the urban neighborhood such as coffee shops, theaters, hotels, malls, department stores, warehouses, office buildings, universities, police and fire departments, museums, community centers, indoor fitness facilities, golf courses, sports tracks, parking lots, and water bodies.

The spatial analysis reported an unequal distribution of intersections in the study area. Thus the block sizes vary from short to super-long blocks, which results in higher trip lengths. Additionally, low connectivity due to cul-de-sacs and looped streets can discourage walking within the community. Lack of appropriate walking infrastructure due to irregular building setback and driveways, as well as the non-existence of bike lanes and lack of traffic calming design in the community makes it unsafe to walk within the neighborhood. Although the Abu Dhabi Road Design Manual [54] proposes a street cross-section that includes these elements for streets in Abu Dhabi, the study area lacks pedestrian-oriented design that can encourage walking. Hence the Abu Dhabi Department of Municipalities and Transportation should make efforts to develop the streets with Abu Dhabi neighborhoods to make them conducive for walking and biking, and discourage the use of cars.

Roads cover a significant portion of the open area. The landscaped area is just about $15 \%$, with only one public park within the neighborhood. This makes the community suitable for cars and less for physical activity for both adults and children in the study area. Additional parks and inclusion of 
aesthetically appealing street design elements such as trees to shade the pedestrians, water fountains, and picnic tables can encourage effective use of the open space.

In conclusion, the outcome from the spatial analysis and the audit tool, in addition to the survey responses, indicate a need to provide more opportunities for residents to walk, recreate, and socialize. Specific destinations such as retail and the recreational and aesthetic design of the neighborhood streets, buildings, and parks can provide opportunities to walk and bike and achieve higher levels of physical activity while discouraging the use of private cars for short-distance trips. This can enhance the social capital and neighborhood satisfaction and achieve the goals of Abu Dhabi 2030, which aim to create a well-connected pedestrian network to diverse destinations in order to form a healthy and safe community in Abu Dhabi.

Author Contributions: Conceptualization by P.M.; methodology by A.A.-A., P.M. and K.A.; software analysis by A.A.-A.; formal analysis by P.M.; investigation by A.A.-A., P.M. and K.A.; data resources from K.A.; data curation by A.A.-A.; writing-original draft preparation by A.A.-A.; writing-review and editing by P.M. and K.A.; supervision by P.M. All authors have read and agreed to the published version of the manuscript."

Funding: This research received no external funding

Acknowledgments: This research received no specific grant from any funding agency in the public, commercial, or not-for-profit sectors.

Conflicts of Interest: The authors declare no conflict of interest.

\section{References}

1. Sherer, P.M. Why America needs more city parks and open space. 2003. Available online: http://www. eastshorepark.org/benefits_of_parks\%20tpl.pdf (accessed on 15 January 2020).

2. York Cornwell, E.; Behler, R.L. Urbanism, neighborhood context, and social networks. City Community 2015, 14, 311-335. [CrossRef]

3. Mitchell, C.U.; LaGory, M. Social capital and mental distress in an impoverished community. City Community 2002, 1, 199-222. [CrossRef]

4. Koohsari, M.J.; Mavoa, S.; Villanueva, K.; Sugiyama, T.; Badland, H.; Kaczynski, A.T.; Owen, N.; Giles-Corti, B. Public open space, physical activity, urban design and public health: Concepts, methods and research agenda. Health Place 2015, 33, 75-82. [CrossRef]

5. Trepci, E.; Maghelal, P.; Azar, E. Effect of densification and compactness on urban building energy consumption: Case of a Transit-Oriented Development in Dallas, TX. Sustain. Cities Soc. 2020, 56, 101987. [CrossRef]

6. Francis, M. Urban Open Space: Designing for User Needs; Island Press: Washington, DC, USA, 2003.

7. Burrows, E.; O'Mahony, M.; Geraghty, D. How urban parks offer opportunities for physical activity in Dublin, Ireland. Int. J. Environ. Res. Public Health 2018, 15, 815. [CrossRef]

8. Pimenta, A.; Maghelal, P.; Alawadi, K. Are Transit-Oriented Developments Effective Neighborhood Design Models to Help Meet the Recommended Weekly Physical Activity Levels? Case of Abu Dhabi. Int. J. Sustain. Transp.. (forthcoming).

9. Maghelal, P.; Natesan, P.; Naderi, J.R.; Kweon, B.S. Investigating the use of virtual reality for pedestrian environments. J. Archit. Plan. Res. 2011, 28, 104-117.

10. Song, C.; Ikei, H.; Igarashi, M.; Takagaki, M.; Miyazaki, Y. Physiological and psychological effects of a walk in urban parks in fall. Int. J. Environ. Res. Public Health 2015, 12, 14216-14228. [CrossRef] [PubMed]

11. Phaneuf, D.J.; Smith, V.K.; Palmquist, R.B.; Pope, J.C. Integrating property value and local recreation models to value ecosystem services in urban watersheds. Land Econ. 2008, 84, 361-381. [CrossRef]

12. Shaw, R.J.; Čukić, I.; Deary, I.J.; Gale, C.R.; Chastin, S.F.; Dall, P.M.; Dontje, M.L.; Skelton, D.A.; Macdonald, L.; Der, G. The influence of neighbourhoods and the social environment on sedentary behaviour in older adults in three prospective cohorts. Int. J. Environ. Res. Public Health 2017, 14, 557. [CrossRef] [PubMed]

13. Statistical Yearbook of Abu Dhabi 2017. Statistical Center of Abu Dhabi. 2017. Available online: https: $/ /$ www.scad.gov.ae/en/pages/generalpublications.aspx?releaseid=973\&publicationid $=79 \&$ topicid $=($ accessed on 15 January 2020). 
14. Abu Dhabi Plan 2030. Charrette One Proceeding Book Final. 2013. Available online: https://www.ecouncil. ae/PublicationsEn/plan-abu-dhabi-full-version-EN.pdf (accessed on 15 January 2020).

15. Almardood, M.; Maghelal, P. Enhancing the use of transit in arid regions: Case of Abu Dhabi. Int. J. Sustain. Transp. 2020, 14, 375-388. [CrossRef]

16. Alawadi, K.; Benkraouda, O. What happened to Abu Dhabi's urbanism? The question of regional integration. J. Urban Des. 2018, 23, 367-394. [CrossRef]

17. Scoppa, M.; Bawazir, K.; Alawadi, K. Walking the superblocks: Street layout efficiency and the sikkak system in Abu Dhabi. Sustain. Cities Soc. 2018, 38, 359-369. [CrossRef]

18. Scoppa, M.; Bawazir, K.; Alawadi, K. Straddling boundaries in superblock cities. Assessing local and global network connectivity using cases from Abu Dhabi, UAE. Transp. Res. Part A Policy Pract. 2019, 130, 770-782. [CrossRef]

19. Sugiyama, T.; Leslie, E.; Giles-Corti, B.; Owen, N. Associations of neighbourhood greenness with physical and mental health: Do walking, social coherence and local social interaction explain the relationships? J. Epidemiol. Community Health 2008, 62, e9. [CrossRef]

20. Sung, H.; Lim, J.; Mun, J.; Kim, Y. Objective versus Self-Reported Physical Activity and Cardiovascular Disease Risk Factors. Korean J. Sports Med. 2020, 38, 28-36. [CrossRef]

21. Godbey, G.C.; Mowen, A.J. The Role of Parks and Recreation in Promoting Physical Activity and Health. Franklin County Healthier Communities Through Active Living Summit. Kauffman Station PA: Chambersburg, PA, USA, 2003.

22. Van Dyck, D.; Cardon, G.; Deforche, B.; Giles-Corti, B.; Sallis, J.F.; Owen, N.; De Bourdeaudhuij, I. Environmental and psychosocial correlates of accelerometer-assessed and self-reported physical activity in Belgian adults. Int. J. Behav. Med. 2011, 18, 235-245. [CrossRef]

23. Hur, M.; Nasar, J.L. Physical upkeep, perceived upkeep, fear of crime and neighborhood satisfaction. J. Environ. Psychol. 2014, 38, 186-194. [CrossRef]

24. Leslie, E.; Saelens, B.; Frank, L.; Owen, N.; Bauman, A.; Coffee, N.; Hugo, G. Residents' perceptions of walkability attributes in objectively different neighbourhoods: A pilot study. Health Place 2005, 11, 227-236. [CrossRef]

25. Basolo, V.; Strong, D. Understanding the neighborhood: From residents' perceptions and needs to action. Hous. Policy Debate 2002, 13, 83-105. [CrossRef]

26. Ross, A.; Searle, M. A conceptual model of leisure time physical activity, neighborhood environment, and sense of community. Environ. Behav. 2019, 51, 749-781. [CrossRef]

27. Kweon, B.S.; Sullivan, W.C.; Wiley, A.R. Green common spaces and the social integration of inner-city older adults. Environ. Behav. 1998, 30, 832-858. [CrossRef]

28. Sullivan, W.C.; Kuo, F.E.; Depooter, S.F. The fruit of urban nature: Vital neighborhood spaces. Environ. Behav. 2004, 36, 678-700. [CrossRef]

29. Cohen, D.A.; Ashwood, J.S.; Scott, M.M.; Overton, A.; Evenson, K.R.; Staten, L.K.; Porter, D.; McKenzie, T.L.; Catellier, D. Public parks and physical activity among adolescent girls. Pediatrics 2006, 118, e1381-e1389. [CrossRef] [PubMed]

30. Kaczynski, A.T.; Potwarka, L.R.; Smale, B.J.; Havitz, M.E. Association of parkland proximity with neighborhood and park-based physical activity: Variations by gender and age. Leis. Sci. 2009, 31, 174-191. [CrossRef]

31. Melody, S.; Hosking, J.; Woodward, A.; Witten, K.; MacMillan, A.; Field, A.; Baas, P.; Mackie, H. Systematic literature review of built environment effects on physical activity and active transport-an update and new findings on health equity. Int. J. Behav. Nutr. Phys. Act. 2017, 14, 158.

32. Reisz, T. Plans the earth swallows: An interview with Abdulrahman Makhlouf. Portal 2013, 2, 1-17.

33. Saelens, B.E.; Sallis, J.F.; Black, J.B.; Chen, D. Neighborhood-based differences in physical activity: An environment scale evaluation. Am. J. Public Health 2003, 93, 1552-1558. [CrossRef]

34. Slater, S.; Full, K.; Fitzgibbon, M.; Floyd, M. Parks and Recreation Areas Self-Report Survey. Available online: http://activelivingresearch.org/parks-and-recreation-areas-self-report-survey (accessed on 15 January 2020).

35. Grootaert, C.; Narayan, D.; Jones, V.N.; Woolcock, M. Measuring Social Capital: An Integrated Questionnaire; The World Bank: Washington, DC, USA, 2004. 
36. Brownson, R.C.; Hoehner, C.M.; Brennan, L.K.; Cook, R.A.; Elliott, M.B.; McMullen, K.M. Reliability of 2 instruments for auditing the environment for physical activity. J. Phys. Act. Health 2004, 1, 191-208. [CrossRef]

37. Ewing, R.; Cervero, R. Travel and the built environment: A meta-analysis. J. Am. Plan. Assoc. 2010, 76, 265-294. [CrossRef]

38. Maghelal, P. Walking to Transit: Influence of Built Environment at Varying Distances. Inst. Transp. Eng. J. 2011, 81, 38-43.

39. Brown, T.A. Confirmatory Factor Analysis for Applied Research; Guilford Publications: New York City, NY, USA, 2015.

40. Peterson, R.A. A meta-analysis of Cronbach's coefficient alpha. J. Consum. Res. 1994, 21, 381-391. [CrossRef]

41. Hur, M.; Nasar, J.L.; Chun, B. Neighborhood satisfaction, physical and perceived naturalness and openness. J. Environ. Psychol. 2010, 30, 52-59. [CrossRef]

42. Lovejoy, K.; Handy, S.; Mokhtarian, P. Neighborhood satisfaction in suburban versus traditional environments: An evaluation of contributing characteristics in eight California neighborhoods. Landsc. Urban Plan. 2010, 97, 37-48. [CrossRef]

43. Qamhaieh, A.; Chakravarty, S. Global Cities, Public Transportation, and Social Exclusion: A Study of the Bus System in Abu Dhabi. Mobilities 2016, 12, 462-478. [CrossRef]

44. Alawadi, K.; Dooling, S. Challenges and opportunities for participatory planning approaches within Dubai's urban context. J. Urban Int. Res. Placemaking Urban Sustain. 2016, 9, 276-301. [CrossRef]

45. Alawadi, K. Rethinking Dubai's urbanism: Generating sustainable form-based urban design strategies for an integrated neighborhood. Cities 2017, 60, 353-366. [CrossRef]

46. Alawadi, K.; Khanal, A.; Almulla, A. Land, urban form, and politics: A study on Dubai's housing landscape and rental affordability. Cities 2018, 81, 115-130. [CrossRef]

47. Alawadi, K.; Benkraouda, O. The debate over neighborhood density in Dubai: Between theory and practicality. J. Plan. Educ. Res. 2019, 39, 18-34. [CrossRef]

48. Beal, L.; Séraphin, H.; Modica, G.; Pilato, M.; Platania, M. Analysing the Mediating Effect of Heritage Between Locals and Visitors: An Exploratory Study Using Mission Patrimoine as a Case Study. Sustainability 2019, 11, 3015. [CrossRef]

49. Tresidder, M. Using GIS to Measure Connectivity: An Exploration of Issues; Portland State University: Portland, OR, USA, 2005.

50. Bratman, G.N.; Anderson, C.B.; Berman, M.G.; Cochran, B.; Vries, S.D.; Flanders, J.; Folke, C.; Frumkin, H.; Gross, J.J.; Hartig, T.; et al. Nature and mental health: An ecosystem service perspective. Science 2019, 5, eaax0903. [CrossRef] [PubMed]

51. Alawadi, K. A return to the old landscape? Balancing physical planning ideals and cultural constraints in Dubai's residential neighborhoods. J. Hous. Built Environ. 2019, 34, 235-263. [CrossRef]

52. Alawadi, K. Place attachment as a motivation for community preservation: The demise of an old, bustling, Dubai community. Urban Studies 2017, 54, 2973-2997. [CrossRef]

53. Alawadi, K. Urban redevelopment trauma: The story of a Dubai neighbourhood. Built Environ. 2014, 40, 357-375. [CrossRef]

54. Abu Dhabi Urban Street Design Manual. 2013. Available online: https://isocarp.org/app/uploads/2014/05/ AfE_2013_4-UPC.pdf (accessed on 15 January 2020).

(C) 2020 by the authors. Licensee MDPI, Basel, Switzerland. This article is an open access article distributed under the terms and conditions of the Creative Commons Attribution (CC BY) license (http://creativecommons.org/licenses/by/4.0/). 